\title{
CARBON DIOXIDE REMOVAL USING AMMONIA IN BIOGAS UPGRADING AND PURIFICATION
}

\author{
O. I. MAILE ${ }^{a \star}$ AND E. MUZENDA ${ }^{a, b}$
}

\begin{abstract}
An alternative source of energy like biogas has become of interest to reduce the dependence on depleting fossil fuels for the source of energy. It is environmentally friendly and can be generated from various biomass wastes. It consists of $\mathrm{CH}_{4}(55 \%-65 \%)$ and $\mathrm{CO}_{2}(35 \%-45 \%)$ with a calorific value of $22000-25000 \mathrm{~kJ} / \mathrm{m}^{3}$ when raw and after $\mathrm{CO}_{2}$ is removed, the methane gas has a calorific value up to $39000 \mathrm{~kJ} / \mathrm{m}^{3}$ and is referred to as biomethane. Ammonia is used as an absorbent in chemical scrubbing to remove $\mathrm{CO}_{2}$ from biogas. A continuous system consisting of $1 \mathrm{~L}$ digester was used for biogas production which was bubbled through an absorbent in $500 \mathrm{~mL}$ gas washing bottle at a constant temperature in a water bath. The obtained biomethane potential was found to be $0.387 \mathrm{~m}^{3} \mathrm{CH}_{4} / \mathrm{kg}$ VS which simply means that more methane gas can be obtained when using ammonia for absorption. An increase in the gas flow rate leads to an increase in the mass transfer coefficient resulting in an increase in the rate of absorption. The initial $\mathrm{CO}_{2}$ concentration affects the removal efficiency because more work needs to be done for biogas with a high initial concentration of $\mathrm{CO}_{2} . \mathrm{NH}_{3}$ has better absorption capacity because higher biogas purity was achieved at lower $\mathrm{NH}_{3}$ concentration. The removal efficiency for $\mathrm{NH}_{3}$ increased from $69 \%-79 \%$ on average with $\mathrm{CH}_{4}$ concentration reaching over $85 \%$ vol. This is equivalent to a calorific value ranging from $25-33.5 \mathrm{MJ} / \mathrm{Nm}^{3}$ which is promising in terms of the gas ability to run in an automobile engine.
\end{abstract}

Keywords: absorption, concentration, efficiency, energy, fuel

a University of Johannesburg, Faculty of Engineering and Built Environment, Department of Chemical Engineering.

${ }^{\mathrm{b}}$ Botswana International University, Faculty of Engineering and Technology, Department of Chemical and Metallurgical Engineering.

*Corresponding author: ireenmaile@yahoo.com 


\section{INTRODUCTION}

Energy is an important part of our daily lives. As a result, the world is facing energy crisis due to depleting oil reserves, emissions from this energy source and unstable prices among other several negative factors. An alternative source of energy like biogas has become of interest as it is environmentally friendly in additional to other several advantages.

Raw biogas as generated from various biomass wastes consists of $\mathrm{CH}_{4}(55 \%-65 \%)$ and $\mathrm{CO}_{2}(35 \%-45 \%)$. Its calorific value when raw is $22000-$ $25000 \mathrm{~kJ} / \mathrm{m}^{3}$ and after $\mathrm{CO}_{2}$ is removed, the methane gas has a calorific value of up to $39000 \mathrm{~kJ} / \mathrm{m}^{3}$ and is referred to as biomethane [1, 2]. Ammonia has potential to yield purified gas of over $95 \%$ vol. $\mathrm{CH}_{4}$ which is considered as biomethane and can be used for similar applications as natural gas.

Ammonia is used as an absorbent in chemical scrubbing to remove $\mathrm{CO}_{2}$ from biogas. Though amines like MEA are primarily used, ammonia has number of advantages: higher $\mathrm{CO}_{2}$ loading capacity, no solvent degradation, and equipment corrosion, has low regeneration heat requirements, it has a potential to simultaneously remove $\mathrm{CO}_{2}, \mathrm{SO}_{2}$ and $\mathrm{NO}_{\mathrm{x}}$, suitable for largescale applications, [3-9], it has good oxidative and thermal stabilities [10-13].

Solvent slippage is defined as the amount of liquid solvent that vaporises and is collected with the biomethane. Solvent slippage depends on the volatility of the solvent and the volatility depends largely on the operating temperature [14]. The MEA and $\mathrm{NH}_{3}$ have a high slippage compared to the hydroxides at $22{ }^{\circ} \mathrm{C}$. This means that for the same amount of biogas collected for every digester, the solvent composition is highest for $\mathrm{NH}_{3}$. This also means that the quality of the gas is compromised by the added solvent vapour.

Ammonia is a promising solvent that has been under investigation for carbon capture systems. However, it has a challenge of volatility which may result in solvent slippage. This occurs when some amount of liquid solvent vaporises and collected with the biomethane. The operating temperature plays a huge role as it affects the volatility of the solvent. Alleviating the temperature can limit the slippage of ammonia into the gaseous phase during $\mathrm{CO}_{2}$ absorption [14].

Despite the fact that ammonia is gaining strength and recognition as an absorbent for removing acidic gases from flue gas and also biogas, it has high volatility and low carbon dioxide absorption rate [8, 11]. Promoters are often added to the aqueous ammonia solution to increase the absorption rate. The use of ammonia for removing impurities such as acidic gases from biogas has been researched by other researchers, however higher concentrations have not been extensively studied and this research seeks to address this aspect. 
Table 1. Comparison of different absorption units

\begin{tabular}{|c|c|c|c|c|}
\hline $\begin{array}{c}\text { Absorption } \\
\text { Unit }\end{array}$ & Dimensions & Operating Conditions & $\begin{array}{l}\text { Removal } \\
\text { Efficiency }\end{array}$ & Source \\
\hline $\begin{array}{l}\text { This study: } \\
\text { Buchner flask }\end{array}$ & $500 \mathrm{ml}$ & $\begin{array}{l}\text { Total Pressure Atmospheric 1atm } \\
\text { Temperature } 293-333 \mathrm{~K} \\
\text { Absorbent: } 5-15 \text { wt. } \% \text { ammonia } \\
\mathrm{CO}_{2} \text { concentration: } 46 \text { vol. } \%\end{array}$ & $22-79 \%$ & \\
\hline $\begin{array}{l}\text { Microchannel } \\
\text { reactor }\end{array}$ & $60 \times 0.5 \times 0.5 \mathrm{~mm}^{3}$ & $\begin{array}{l}\text { Total pressure: } 141-401 \mathrm{kPa} \\
\text { Temperature: } 283-303 \mathrm{~K} \\
\text { Absorbent: } 4-10 \text { wt. } \% \text { ammonia } \\
\mathrm{CO}_{2} \text { concentration: } 10 \mathrm{vol} . \% \\
\text { Gas flow rate: } 0.0285 \mathrm{~m}^{3} \mathrm{~h}^{-1} \\
\text { Liquid flow rate: } 0.00012-0.0003 \mathrm{~m}^{3} \mathrm{~h}^{-1}\end{array}$ & $72-97 \%$ & [15] \\
\hline $\begin{array}{l}\text { Packed } \\
\text { column }\end{array}$ & $\begin{array}{l}600 \mathrm{~mm} \text { in height, } \\
100 \mathrm{~mm} \text { in diameter }\end{array}$ & $\begin{array}{l}\mathrm{CO}_{2} \text { partial pressure: } 5-15 \mathrm{kPa} \\
\text { Temperature: } 293-328 \mathrm{~K} \\
\text { Absorbent: } 2-16 \text { wt. } \% \text { ammonia } \\
\mathrm{CO}_{2} \text { concentration: } 5-15 \text { vol. } \% \\
\text { Gas flow rate: } 0.6-1.68 \mathrm{~m}^{3} \mathrm{~h}^{-1} \\
\text { Liquid flow rate: } 0.008-0.024 \mathrm{~m}^{3} \mathrm{~h}^{-1}\end{array}$ & $52-99 \%$ & [22] \\
\hline Spray tower & $\begin{array}{l}350 \mathrm{~mm} \text { in height, } \\
55 \mathrm{~mm} \text { in diameter }\end{array}$ & $\begin{array}{l}\text { Total pressure: } 0.1 \mathrm{MPa} \\
\text { Temperature: } 293-323 \mathrm{~K} \\
\text { Absorbent: } 1-7 \mathrm{wt} \% \text { ammonia } \\
\mathrm{CO}_{2} \text { concentration: } 10-20 \text { vol. } \% \\
\text { Gas flow rate: } 0.2-0.4 \mathrm{~m}^{3} \mathrm{~h}^{-1} \\
\text { Liquid flow rate: } 0.09-0.18 \mathrm{~m}^{3} \mathrm{~h}^{-1}\end{array}$ & - & [17] \\
\hline Bubble column & $\begin{array}{l}305 \mathrm{~mm} \text { in height, } \\
42 \mathrm{~mm} \text { in diameter }\end{array}$ & $\begin{array}{l}\text { Total pressure: } 100 \mathrm{kPa} \\
\text { Temperature: } 283-313 \mathrm{~K} \\
\text { Absorbent: } 0-9 \text { wt. } \% \text { ammonia } \\
\mathrm{CO}_{2} \text { concentration: } 0-15 \text { vol. } \% \\
\text { Gas flow rate: } 0.06 \mathrm{~m}^{3} \mathrm{~h}^{-1} \\
\text { Liquid volume: } 0.15 \mathrm{~L}\end{array}$ & - & [16] \\
\hline $\begin{array}{l}\text { Multistage } \\
\text { spraying tower }\end{array}$ & $\begin{array}{l}540 \mathrm{~mm} \text { in height, } \\
50 \mathrm{~mm} \text { in diameter }\end{array}$ & $\begin{array}{l}\text { Total pressure: } 0.7-1 \mathrm{MPa} \\
\text { Temperature: } 293 \mathrm{~K} \\
\text { Absorbent: } 10-20 \mathrm{wt} \% \text { ammonia } \\
\mathrm{CO}_{2} \text { concentration: } 10-20 \mathrm{vol} . \% \\
\text { Gas flow rate: } 1.8-3.6 \mathrm{~m}^{3} \mathrm{~h}^{-1} \\
\text { Liquid flow rate: } 0.0696-0.1296 \mathrm{~m}^{3} \mathrm{~h}^{-1}\end{array}$ & $72-87 \%$ & [23] \\
\hline
\end{tabular}


The absorption process is affected by the type of absorption unit and mechanism used. The types of columns include; packed column, bubble column, spray tower, multi-stage spraying tower, and microchannel reactor [15-19]. The type of packing also plays a role in the performance of the column; packings can either be random or structured [20]. Experimental flowsheet of a wetted-wall column was previously described [21].

\section{Chemical reactions of the absorption process}

Ammonia reacts with carbon dioxide to form ammonium carbonate in the liquid phase. Reaction 1 and 2 are intermediate reactions which are summarized by reaction 3 . The reactions occurring in the absorption column are shown below:

$$
\begin{aligned}
& \mathrm{CO}_{2(g)}+\mathrm{NH}_{3(a q)} \rightarrow \mathrm{NH}_{2} \mathrm{COOH}_{(a q)} \\
& \mathrm{NH}_{3(a q)}+\mathrm{NH}_{2} \mathrm{COOH}_{(a q)} \rightarrow \mathrm{NH}_{4(a q)}^{+}+\mathrm{NH}_{2} \mathrm{COO}_{(a q)}^{-1} \\
& \mathrm{CO}_{2(g)}+2 \mathrm{NH}_{3(a q)} \rightarrow \mathrm{NH}_{2} \mathrm{COONH}_{4(a q)} \\
& \mathrm{NH}_{2} \mathrm{COO}_{(a q)}^{-}+\mathrm{H}_{2} \mathrm{O}_{(l)} \leftrightarrow \mathrm{HCO}_{3(a q)}^{-}+\mathrm{NH}_{3(a q)} \\
& \mathrm{NH}_{3(a q)}+\mathrm{H}_{2} \mathrm{O}_{(l)} \leftrightarrow \mathrm{NH}_{4(a q)}^{+}+\mathrm{OH}_{(a q)}^{-1}
\end{aligned}
$$

\section{RESULTS AND DISCUSSION}

Ammonia was used to absorb carbon dioxide from biogas, concentrations were varied, and temperature effect was studied and discussed. The concentration studied were 10,15 , and $20 \%$ as shown in Table 1 . The removal efficiency was also calculated and included in Table 1. It is observed that the absorption rate increases with increasing ammonia concentration, which is in agreement with the findings of [22].

Ammonia is a good carbon dioxide absorber and it is potent to remove the carbon dioxide from the biogas to produce methane rich gas. The cumulative methane yield was realized to be increasing with increasing aqueous ammonia concentration [22, 24, 25]. The obtained biomethane potential was found to be $0.387 \mathrm{~m}^{3} \mathrm{CH}_{4} / \mathrm{kg}$ VS which simply means that more methane gas can be obtained when using ammonia for absorption.

\section{A. The effect of solvent concentration on absorption}

The results obtained from the tests that were done are also represented graphically in Figure 2 to Figure 4. An overall observation from the above graphs is that the absorption of carbon dioxide didn't occur steadily. This can be 
attributed to the gas flow rate in the system which affects the rate of absorption. An increase in the gas flow rate leads to an increase in the mass transfer coefficient resulting in an escalation in the speed of the absorption process. Thus, it can be said that the days the absorption was higher the gas flow rate was high also because an increase in the gas flow rate improves the absorption rate and the opposite is true for the days the absorption was low.

The surface/contact area which is the gas-liquid interphase plays a huge role in the overall absorption rate and the mass transfer coefficient. The tests yielded an average methane content in the gas of $75 \%, 79 \%$, and $83 \%$ for the $10 \%, 15 \%$, and $20 \%$ ammonia concentration respectively. This can be a result of an increase in the active ammonia present in the solution due to an increase in concentration which is able to diffuse in the gas-liquid interface reacting with the carbon dioxide. This further leads to a decrease in the mass transfer resistance resulting in increased absorption rate.

\section{B. Effect of liquid phase temperature on absorption}

The effect of the solvent temperature on the absorption process was studied. The investigated temperatures were room temperature, $30{ }^{\circ} \mathrm{C}$ and $40^{\circ} \mathrm{C}$. Figure 5 shows the results obtained by comparing the gas quality from the different temperatures. The methane composition and yield increased with increasing temperature.

The results are further summarised in Table 4. The increase in $\mathrm{CH}_{4}$ composition between room temperature and $30^{\circ} \mathrm{C}$ is not significant, however, there is an improvement in the $40{ }^{\circ} \mathrm{C}$ study. The $\mathrm{CH}_{4}$ composition recorded the highest at $40^{\circ} \mathrm{C}$. Furthermore, temperature helps in reducing the viscosity of the solvent to improve the absorption performance. However, the temperature of ammonia solvent and the absorption column should not be high above $60{ }^{\circ} \mathrm{C}$ in order to avoid slippage. In addition, higher temperatures also lead to decomposition of the ammonium bicarbonate salt at a temperature above the acceptable range of $20{ }^{\circ} \mathrm{C}$ to $40{ }^{\circ} \mathrm{C}$. This is due to the reversibility of the reaction of carbon dioxide and ammonia, in which increases in temperature favours the forward reaction [26]. However, a further increase beyond $40{ }^{\circ} \mathrm{C}$ shifts the equilibrium to the reverse reaction.

\section{Effect of solvent concentration on removal efficiency}

The $\mathrm{CO}_{2}$ removal efficiency for ammonia was calculated using Eq. 6 and the results are represented in Figures 6 and 7 . The removal efficiency is influenced by many factors including, the concentration of aqueous ammonia, gas flow rate, and the ammonia to carbon dioxide molar ratio. The highest removal efficiency recorded was $66 \%$ which is contrary to what was obtained by reference [27]. It could be attributed to the process setup as a spray column 
was used and it provides a good gas-liquid interface for the contact and thus resulting in high removal efficiency. It can be observed that the gas flow rate also plays a role in $\mathrm{CO}_{2}$ removal. However, an increase in the gas flow rate leads to an increase in the removal efficiency. The molar ratio can either improve the efficiency or reduce it, hence it needs to be cautiously kept at an appropriate point.

$$
\eta_{\mathrm{CO}_{2}}=\left(1-\frac{C O_{2_{\text {pur }}}}{C O_{2_{\text {raw }}}}\right) \times 100 \%
$$

Where:

Пco2- carbon dioxide removal efficiency

$\mathrm{CO}_{2 \text { pur }}$ carbon dioxide content of the purified sample

$\mathrm{CO}_{2 \text { raw }}$ carbon dioxide of the raw sample

The experimental configuration and type of absorber affect the carbon dioxide removal efficiency. This is illustrated in Table 1, where the removal efficiency for a packed column had a higher removal efficiency. Although high removal efficiencies were obtained by the other studies, it can be attributed to the operating conditions and initial concentration of carbon dioxide which was low in their case. Furthermore, the increase in concentration may lead to a decline in the removal efficiency as it leads to increase in viscosity which may contribute to the solvent loss.

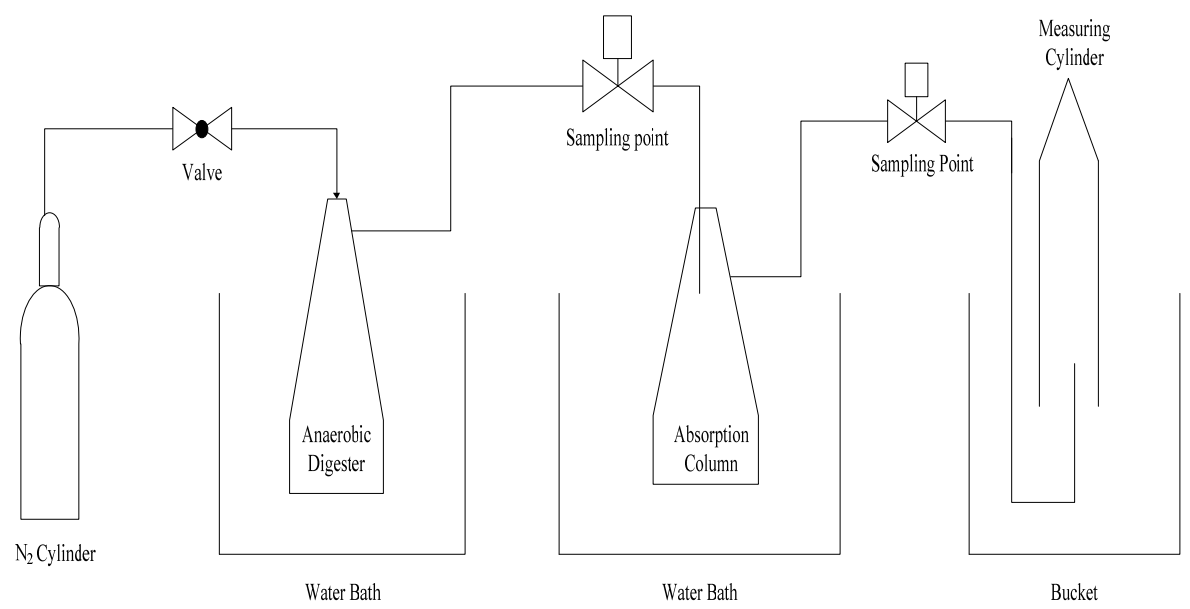

Figure 1. Schematic diagram of laboratory set up for absorption in aqueous ammonia 


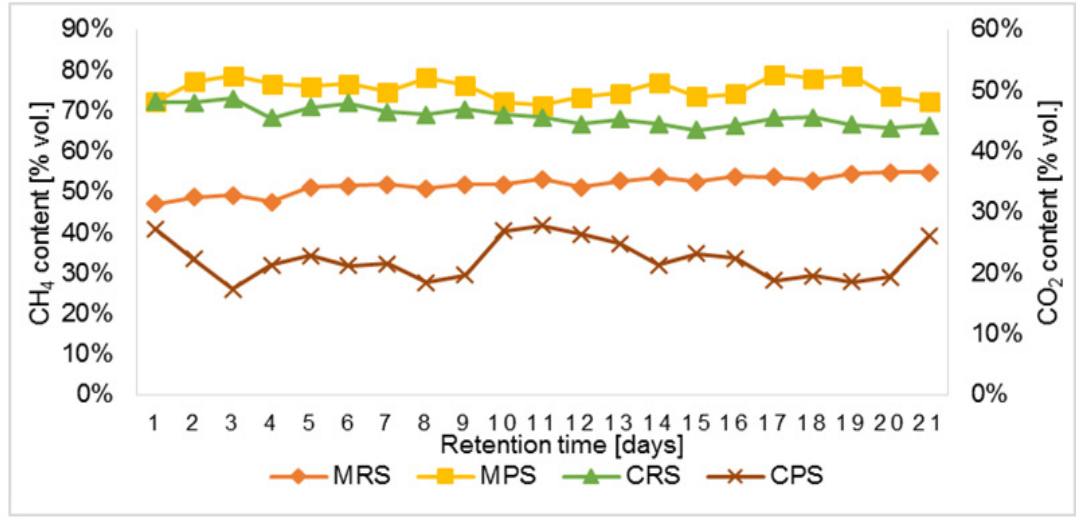

Figure 2. Absorption of $\mathrm{CO}_{2}$ with $\mathrm{NH}_{3}$ at $10 \%$ concentration.

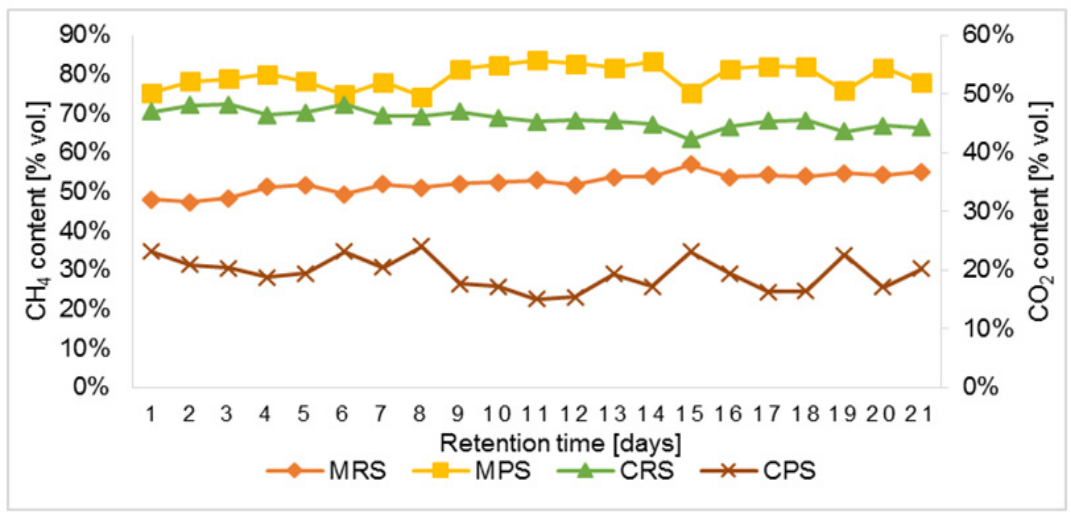

Figure 3. Absorption of $\mathrm{CO}_{2}$ with $\mathrm{NH}_{3}$ at $15 \%$ concentration.

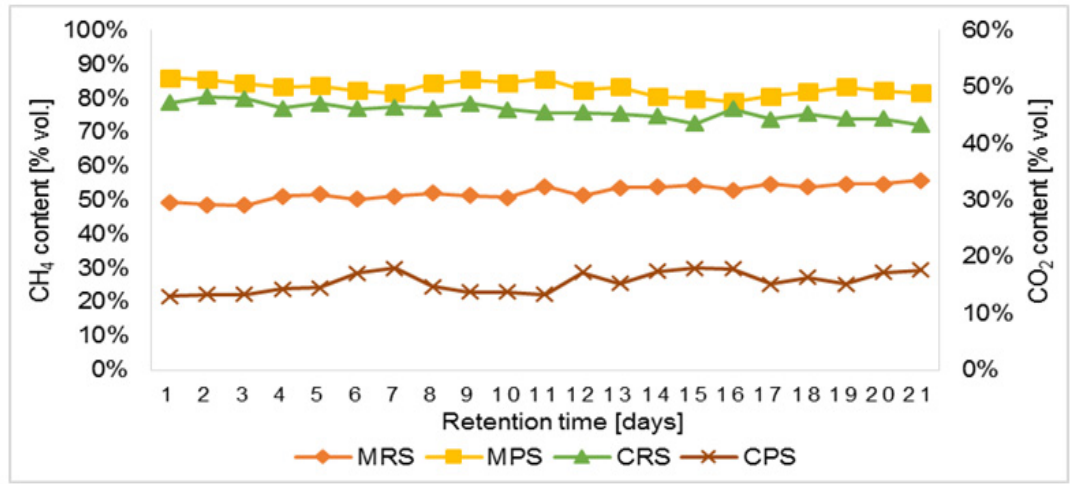

Figure 4. Absorption of $\mathrm{CO}_{2}$ with $\mathrm{NH}_{3}$ at $20 \%$ concentration. 
Table 2. Notation table for Figures 2-4

\begin{tabular}{ll}
\hline \hline Acronym & Meaning \\
\hline MRS & Methane $\left(\mathrm{CH}_{4}\right)$ content of the raw sample \\
MPS & Methane $\left(\mathrm{CH}_{4}\right)$ content of the purified sample \\
CRS & Carbon dioxide $\left(\mathrm{CO}_{2}\right)$ content of the raw sample \\
CPS & Carbon dioxide $\left(\mathrm{CO}_{2}\right)$ of the purified sample \\
\hline
\end{tabular}

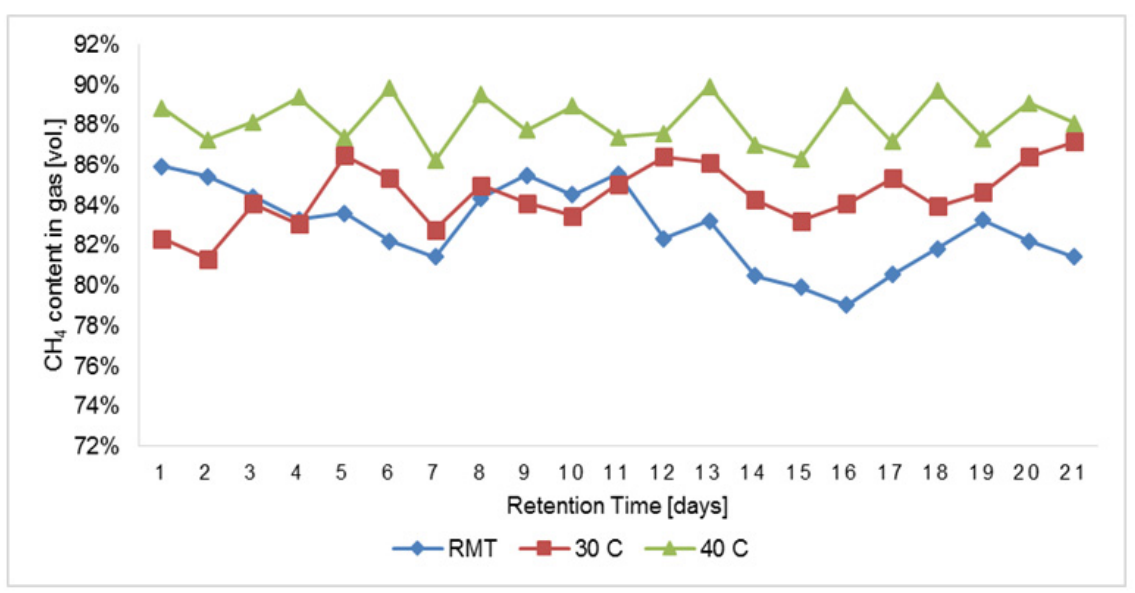

Figure 5. The effect of temperature on methane content in biogas purification

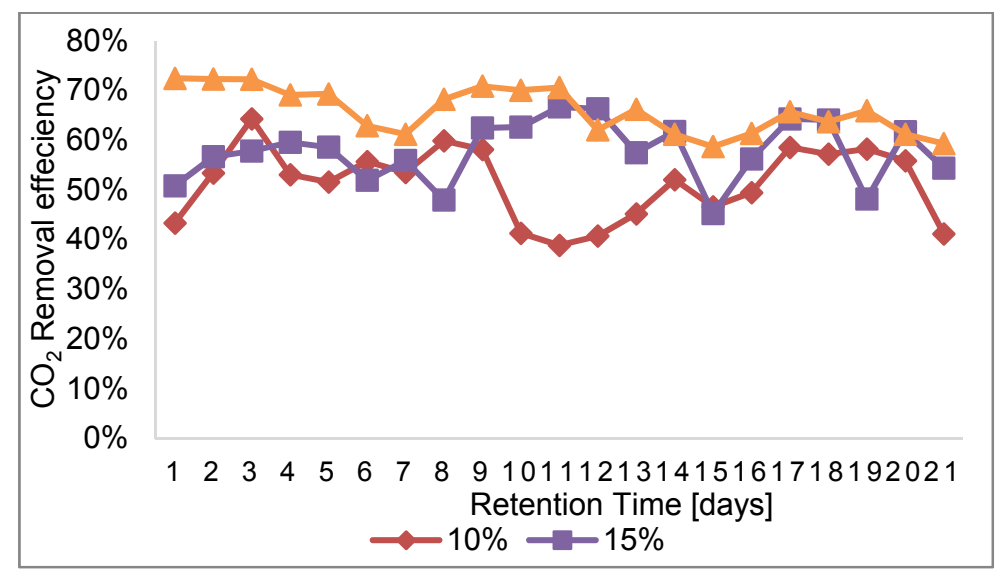

Figure 6. Effect of concentration on carbon dioxide removal efficiency 


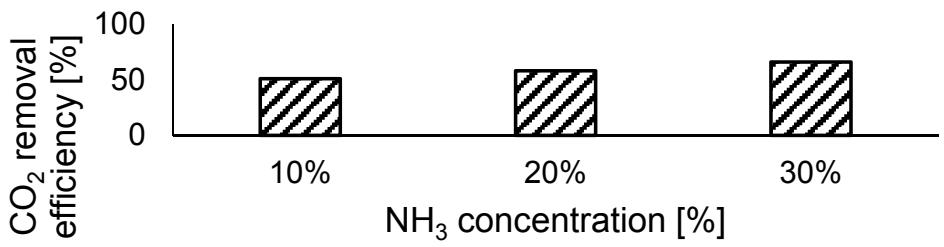

Figure 7. Carbon dioxide removal efficiency

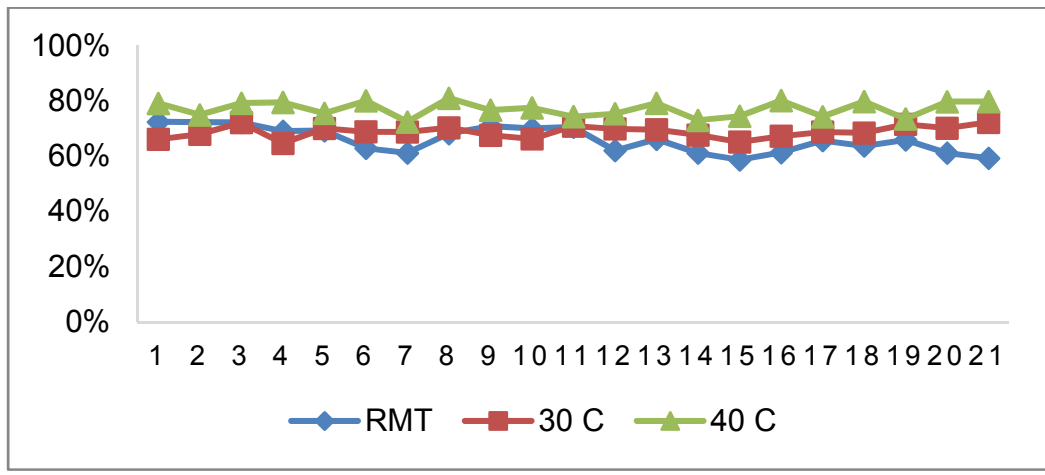

Figure 8. Effect of temperature on carbon dioxide removal efficiency

Table 3. Performance of $\mathrm{NH}_{3}$ in $\mathrm{CO}_{2}$ absorption

\begin{tabular}{cccccc}
\hline \hline Gas & Composition & Raw Biogas & $10 \%$ & $15 \%$ & $20 \%$ \\
\hline $\mathrm{CH}_{4}$ & $\%$ & 52 & 75 & 79 & 83 \\
$\mathrm{CO}_{2}$ & $\%$ & 46 & 22 & 19 & 16 \\
$\eta$ & $\%$ & - & 51 & 58 & 66 \\
\hline
\end{tabular}

Table 4. Summary of results on temperature variation

\begin{tabular}{cccc}
\hline \hline Parameter & $\mathrm{RMT}$ & $30^{\circ} \mathrm{C}$ & $40{ }^{\circ} \mathrm{C}$ \\
\hline $\mathrm{CH}_{4}$ & 83 & 85 & 88 \\
$\mathrm{CO}_{2}$ & 16 & 14 & 11 \\
$\eta$ & 66 & 69 & 77 \\
\hline
\end{tabular}




\section{CONCLUSIONS}

Chemical absorption technique has been widely used to remove impurities from biogas as it is deemed to be cheap and effective. An increase in the concentration of ammonia enhanced the rate of absorption, which was mainly because the concentration of the reacting ions in the aqueous ammonia solution increases and contact between the gas-liquid interface is increased. The raw biogas had on average $52 \% \mathrm{CH}_{4}$ vol. which improved to $83 \% \mathrm{CH}_{4}$ vol. after absorption. The $\mathrm{CO}_{2}$ removal efficiency improved from $22 \%$ to $66 \%$. The initial $\mathrm{CO}_{2}$ concentration affects the removal efficiency because more work needs to be done for biogas with a high initial concentration of $\mathrm{CO}_{2} . \mathrm{NH}_{3}$ has better absorption capacity because higher purity was obtained using even lower absorbent concentration.

The absorption rate also improved with an increase in temperature. The removal efficiency for $\mathrm{NH}_{3}$ increased from $69 \%-79 \%$ on average with $\mathrm{CH}_{4}$ concentration reaching over $85 \%$ vol. This is equivalent to a calorific value ranging from $25-33.5 \mathrm{MJ} / \mathrm{Nm}^{3}$ which is promising in terms of the gas ability to run in an automobile engine. The less the impurities in the gas the more or easily combustible it becomes. Ammonia has high absorption capacity and can also be regenerated with ease, it also has an advantage of the use of ammonium carbonates as inorganic fertilizers.

\section{EXPERIMENTAL SECTION}

A continuous system was used according to literature data [15]. 1L digester was used for biogas production which was bubbled through an absorbent in $500 \mathrm{~mL}$ gas washing bottle. The digester was kept in a water bath to maintain a constant operating temperature throughout the experiment. To study the effect of temperature on absorption the absorption column was also kept in a water bath and the temperature varied accordingly. Nitrogen gas was used to purge and create anaerobic conditions in the system. A valve is used to let the $\mathrm{N}_{2}$ gas into the digester and closed after purging is done. Two sampling points in a form of T's closed with a septa between the processes, for the raw biogas and the purified gas. The gas exiting the absorption unit goes to $1 \mathrm{~L}$ measuring cylinder for volume capturing using downward displacement.

Ammonia was used as an absorbent supplied by Sigma-Aldrich (South Africa). $10-20 \% w t$ solution was used for the purification in a $500 \mathrm{~mL}$ vessel which was kept at constant temperature. The gas exiting the absorption column was analysed using Gas Chromatography (SRI 8610C GC) equipped with FID and TCD detectors, packed with 6' Hayesep-D/ 6' Molecular Sieve-13 X. $1 \mathrm{~mL}$ SGE gas tight syringe was used to draw the gas for sampling from the septa. 


\section{ACKNOWLEDGMENTS}

The authors are indebted to late Dr. Habtom Tesfagiorgis who supervised the Masters studies of the first author and research activities where this current work is drawn from. The Botswana International University of Science and Technology, the South African National Energy Development Institute (SANEDI), Global Excellence Scholarship (GES), the City of Johannesburg (CoJ), the department of Chemical Engineering and the Process Energy and Environmental Technology Station (PEETS) at the University of Johannesburg acknowledged for supporting this research.

\section{REFERENCES}

1. Yin, B., L.M. Chen, and Q.P. Kong, Modern Chemical Industry, 2009, 29(11): p. 28.

2. Xiao, Y., et al., $\mathrm{CO}_{2}$ Chinese Journal of Chemical Engineering 2014, 22, 950.

3. Zhao, Z., H. Dong, and X. Zhang,. Chinese Journal of Chemical Engineering, 2012, 20(1), 120.

4. Zhang, M.K. and Y.C. Guo, International Journal of Greenhouse Gas Control, 2013, 16, 61.

5. Puxty, G., R. Rowland, and M. Attalla, Chemical Engineering Science, 2010, 65, 915.

6. Mores, P., N. Scenna, and S. Mussati, International Journal of Greenhouse Gas Control, 2012, 6, 21.

7. M S Chen, S. Huihui, Z. Bin, C. Gongda, Chemical Engineering Research and Design, 2013, 91, 2775.

8 V. Darde, W.J.M. van Well, P.L. Fosboel, E.H. Stenby, K Thomsen, International Journal of Greenhouse Gas Control 2011, 5, 1149.

9 V. Darde, B. Maribo-Mogensen, W.J.M. van Well, E.H. Stenby, K. Thomsen, International Journal of Greenhouse Gas Control, 2012, 10, 74.

10. F. Qin, S. Wang, I. Kim, H.F. Svendsen, C. Chen International Journal of Greenhouse Gas Control 2011, 5, 405.

11. M. Fang, Q. Xiang, X. Zhou, Q. Ma, Z. Luo, Energy Procedia 2014, 61, 2284.

12. P.W.J. Derks, G.F. Versteeg, Energy Procedia, 2009, 1139.

13. H. Bai, A.C. Yeh, Industrial Engineering Chemical Research, 1997, 36, 2490.

14. W.M. Budzianowski, $\mathrm{CO}_{2}$ Environment Protection Engineering, 2011, 37, 5.

15. N. Kittiampon, A. Kaewchada, A. Jaree, International Journal of Greenhouse Gas Control, 2017, 63, 431.

16. S. Ma, G. Chen, S. Zhu, T. Han, W. Yu Applied Energy, 2016, 162, 354.

17. S. Ma, H. Song, M. Wang, J. Yang, B. Zang, Chemical Engineering Research and Design, 2013, 91(7), 1327. 
18. S. Ma, B. Zang, H. Song, G. Chen, J. Yang, International Journal of Heat and Mass Transfer, 2013, 67, 696.

19. L.S. Tan, A.M. Shariff, K.K. Lau, M.A. Bustam, Journal of Industrial and Engineering Chemistry, 2012, 18(6), 1874.

20. B. Zhao, Y. Su, W. Tao, L. Li, Y. Peng, International Journal of Greenhouse Gas Control, 2012, 9, 355.

21. J. Liu, S. Wang, B. Zhao, H. Tong, C. Chen, Energy Procedia, 2009, 1(1), 933.

22. Q. Zeng, Y. Guo, Z. Niu, W. Lin, Fuel Processing Technology, 2013, 108, 76.

23. B. Zhao, Y. Su, G. Cui, Energy, 2016, 102, 106.

24. P.S. Nair, P.P. Selvi, International Journal of Scientific and Research Publications, 2014, 4(4), 1.

25. C.H. Hsu, H. Chu, C.M. Cho, Journal of Air \& Waste Management Association, 2012, 53, 246.

27. A. McLeod, B. Jefferson, E.J. McAdam, Water Research, 2014, 67, 175.

28. Z.Q. Niu, Y.C. Guo, W.Y. Lin, Science China Technological Sciences, 2010, $53,117$. 